\title{
Reconversión de cultivos como resultado de la presencia de huanglongbing en Colima, México
}

\author{
Crop reconversion as a result of the presence of huanglongbing \\ in Colima, Mexico
}

\author{
Guadalupe Rebeca Granados-Ramírez ${ }^{1}$ \\ Universidad Nacional Autónoma de México, México \\ Raciel Hernández-Hernández ${ }^{2}$ \\ Universidad Autónoma Chapingo, México
}

\section{Resumen}

El estado de Colima se le conoce como el principal productor de limón. En 2010 se detectó la presencia del Huanglonbing (HLB), enfermedad de los brotes amarillos en esta región, misma que ha ocasionado pérdidas progresivas. Hasta el momento no se conoce cura y la baja rentabilidad de la producción provoca que el agricultor decida retirar la plantación. Así, la reconversión productiva, implica modificar el patrón de producción, mediante el establecimiento de cultivos alternativos con mayor viabilidad agronómica, social y rentabilidad económica. El objetivo de este trabajo fue cuantificar los cambios en los cultivos, además de valorar el potencial de las nuevas plantaciones. Para monitorear, identificar y cuantificar los cambios; se recurrió al análisis de imágenes de satélite, formación y análisis de bases de datos agrícolas, entrevistas y mediciones en campo. Entre otros se comprobó un progresivo aumento en el reemplazo de cultivos, se han sustituido alrededor de 5000 ha de cítricos, lo que ha significado una reducción de 84,721 ton en el volumen de producción del limón mexicano y una pérdida de 302,636,729 de pesos aproximadamente. La superficie de cultivos emergentes como papaya y piña va en aumento y han representado mayores ingresos económicos para los productores.

1 Doctora en Geografía por la Universidad Nacional Autónoma de México. Investigador del Instituto de Geografía. UNAM, Circuito de la Investigación Científica, Ciudad Universitaria, 04510, México, D.F. E-mail: rebeca@igg.unam.mx. *Autor de correspondencia

2 Becario de Doctorado en Geografía, UNAM. Profesor-Investigador de Parasitología Agrícola, Universidad Autónoma Chapingo. Km 38.5 carretera México-Texcoco, Chapingo, Estado de México.

Este artículo corresponde a la ponencia presentada en el 35th Conference of Latin American Geographers realizada en San José, Costa Rica del 20 al 22 de mayo del 2018. 
Palabras clave: citricultura, limón Mexicano, HLB, reducción de rendimientos, reconversión productiva

\begin{abstract}
The state of Colima is known as the main producer of lemon. In 2010 the presence of citrus greening or Huanglonbing (HLB), a disease affecting, was detected in this region and has since translated into multiplying losses. Up to this date, no cure for it is known and the low profitability of the production forces growers to withdraw their crops. Therefore, the productive reconversion modifies the production pattern by establishing alternate crops with a higher agronomic and social feasibility, as well as a better economic profitability. The main goal of this research was to quantify the changes in the crops and to assess the potential of introducing new ones. In order to monitor, identify and quantify such changes, satellite imagery analysis, building and analysis of agricultural databases, on site measurements and interviews were conducted. An increasing number of crops were substituted, close to 5,000 ha of citrus have been replaced, which amounts to a reduction of 84,721 tons in the production of Mexican lemon and a loss of $\$ 302,636,729 \mathrm{MXN}$, approximately. The area of emergent crops such as papaya and pineapple keeps increasing and has represented a higher income for producers.
\end{abstract}

Keywords: citriculture, Mexican lemon, HLB, yield reduction, productive reconversion

\title{
Introducción
}

\section{Situación actual de la citricultura}

La actividad citrícola en México es considerada la cuarta en importancia a nivel mundial; con una producción de 7.9 millones de toneladas de fruta. China, Brasil y Estados Unidos de América ocupan las primeras posiciones por su alta producción (FAOSTAT, 2018).

De acuerdo con Food and Agriculture Organization of the United Nations (FAO) en 2017 se reportó la existencia de 528,184 ha. de cítricos distribuidas por todo el país; lo que representó una producción de 7.9 millones de toneladas de fruta. A nivel nacional las especies de cítricos de mayor importancia son la naranja dulce $(57.9 \%)$, limón en todas sus especies (30.6\%), mandarina (5.8\%) y toronja (5.5\%) (FAOSTAT, 2018; SIAP, 2018).

Respecto al limón en 2017 la cosecha nacional cerró en 2.5 millones de toneladas lo que posiciona al país como el segundo productor mundial, después de India (SAGARPA, 2018; SIAP, 2018). Cabe resaltar que desde la década de 1940, el estado de Colima se ha destacado como el principal productor a nivel nacional e internacional, debido a su productividad y calidad de la fruta, lo que se reflejó en un importante aporte en el producto interno agrícola del Estado. Esquivel-Chávez et al., (2012) mencionan que ha aportado un valor aproximado del $18 \%$ del PIB. 
Guadalupe Rebeca Granados-Ramírez, Raciel Hernández-Hernández. Reconversión de cultivos como resultado de la presencia de huanglongbing en Colima, México

Su importancia también radica en los empleos que genera, Aproximadamente 3,593 productores cultivan hasta 20,000 ha, y obtienen en promedio 380,000 ton, el $60 \%$ de esta producción da origen a 26 empresas empacadoras, que comercializan el producto en el mercado nacional e internacional para su consumo en fresco. El 40\% restante es transformado en siete agroindustrias que se dedican a la producción de aceites, jugos concentrados, clarificados y pectinas entre otros derivados. La agroindustria citrícola beneficia aproximadamente a 20,000 familias de los municipios de Armería y Tecomán (Manzanilla-Ramírez et al., 2010).

\section{El Huanglongbing, amenaza ancestral de la citricultura}

El Huanglongbing (HLB) o enfermedad de los brotes amarillos, es considerada como la mayor amenaza para la citricultura en el mundo. Esta enfermedad fue descubierta en China hace más de 100 años, tiene como agente causal la bacteria gram negativa del género Candidatus Liberibacter. Existen tres especies $C$. Liberibacter africanus, $C$. Liberibacter americanus y $C$. Liberibacter asiaticus, siendo esta última la más ampliamente distribuida en Asia y América por su tolerancia a altas temperaturas (SAGARPA-SENASICA, 2012).

El HLB es una enfermedad que en condiciones naturales se transmite por los insectos psílidos Trioza erytrae y Diaphorina citri. Actualmente no se conoce cura para los árboles afectados, los que paulatinamente se vuelven decadentes e improductivos hasta que mueren. Hasta 2003, el HLB estuvo restringido a tres regiones geográficas: África, Península de Arabia y Asia (Bové, 2006). En 2004 se registró la presencia de esta enfermedad en el continente Americano en la localidad de Araracuara en Sao Paulo, Brasil; donde se localizó la presencia de Candidatus Liberibacter asiaticus (Colleta et al., 2004); posteriormente, en 2005 se confirmó su detección en Florida, E.U.A. y en 2007 en Cuba.

En México el primer reporte de la enfermedad fue en julio de 2009 en Tizimín, Yucatán; por lo que se activó el plan de emergencia bajo la norma NOM-EM-047-FITO-2009, con estas medidas se esperaba un avance gradual de la enfermedad de sur a norte del país, hecho que no ocurrió ya que en abril de 2010 se da el primer reporte de la enfermedad en árboles de limón mexicano en el huerto comercial "El Ahijadero", municipio de Tecomán, Colima (SAGARPA-SENASICA, 2012); y solo transcurrieron seis meses 
de la primera detección, cuando el Comité Estatal de Sanidad Vegetal de Colima (CESAVECOL) reportó más de 1,200 plantas sintomáticas en más de 140 huertas comerciales en los municipios de Tecomán y Armería.

Actualmente el HLB en el estado de Colima está ampliamente distribuido, se han detectado árboles sintomáticos en todas las zonas productoras de limón mexicano (Robles-González et al., 2013), con base en la normatividad vigente y las experiencias en otras regiones citrícolas de Estados Unidos de América y Brasil; entre otras estrategias implementadas se considera el manejo del HLB para mantener las huertas productivas el mayor tiempo posible y convivir con la enfermedad (Manzanilla-Ramírez et al., 2010).

La presencia del HLB en plantaciones de los Estados Unidos de América, Brasil y México promovió la realización de estudios de impacto potencial en la cadena citrícola, en ellos, se considera aspectos propios del cultivo, su manejo agronómico, y además de variables económicas. Los estudios coinciden en que se han incrementado los costos de producción debido a las múltiples prácticas de manejo aplicadas para prevenir la presencia del HLB (Galvão de Miranda et al., 2012). En Florida uno de los efectos de la presencia del HLB fue la reducción en 50\% de nuevas plantaciones en 2011 y un incremento en los costos de producción hasta en un 33\% (Spreen y Baldwin, 2013).

Estudios epidemiológicos de HLB desarrollados en el mundo (Salcedo-Baca et al., 2010, Galvão de Miranda et al., 2012, Spreen y Baldwin, 2013) coinciden en que una de las variables principales es la magnitud de la superficie establecida de cítricos. Para Colima se determinó que la reducción de rendimiento es dependiente de la severidad de la infección, observándose que cuando el porcentaje de la copa afectada es superior al $50 \%$, los árboles no superan los $30 \mathrm{~kg}$ de rendimiento (Robles-González et al., 2013). Salcedo-Baca et al. (2010) consideraron que de no aplicarse ninguna acción de control en la dispersión del HLB el impacto potencial tendrá gran magnitud lo que ubica al estado de Colima con un riesgo de alto a moderado con pérdidas del orden de los 84,721 ton.

\section{Conversión productiva}

Los cambios de uso del suelo producto de diversos factores físicogeográfico han sido abordados ampliamente (Nieto et al., 2015; Juan y Díaz, 2016); igualmente publicaciones científicas han abordan la dinámica 
Guadalupe Rebeca Granados-Ramírez, Raciel Hernández-Hernández. Reconversión de cultivos como resultado de la presencia de huanglongbing en Colima, México

de los cultivos (Márquez et al., 2002; Ramírez-García et al., 2008), y son escasos los que incorporan aspectos fitosanitarios como causante de dinámica de cultivos.

Los cambios en la dinámica de los cultivos no es un fenómeno reciente; a lo largo de la historia, las variaciones de los fitorecursos se han convertido en una constante de los paisajes agrarios (Juan y Díaz, 2016). En la actualidad constituye una verdadera preocupación sobre todo en aquellas regiones que poseen una larga tradición agrícola y debido a las variaciones en las condiciones climatológicas entre otros, sufren abandono o cambio de uso de suelo. Según Pointereau et al. (2008) citado por Juan y Díaz, (2016) los factores que determinan los cambios son de tipo geográfico, agro-ecológico, demográfico, socio-económico y de respuesta a políticas agrarias nacionales; los enmarcan en dos categorías: las estrictamente físicas y de origen antrópico.

En tanto, García-Ruíz y Lana (2011) señalan la existencia del factor -cambios espontáneos-, mismos que son por decisión directa del propietario, ya que al presentarse una baja rentabilidad de la producción provoca que el agricultor decida retirar el cultivo de sus tierras.

Así, la reconversión productiva representa un instrumento hacia donde puede avanzar la producción agrícola a corto, mediano y largo plazo. De esta forma, se puede cambiar un cultivo perenne por otros perennes o cultivos de ciclo anual. La reconversión implica modificar el patrón de producción, mediante el establecimiento de cultivos alternativos con mayor viabilidad agronómica, social y rentabilidad económica (Zatarain et al., 2005).

\section{Planteamiento metodológico}

En este trabajo el espacio en estudio se centró en los principales municipios productores de limón en México, lo cual obedeció, por ser la primera área del Pacífico Mexicano afectado por el HLB en las plantaciones de limón; generalmente las afectaciones se presentaban en cítricos dulces como la naranja en el Golfo.

Se usó la percepción remota como herramienta de análisis de monitoreo de cultivos, ya que los avances en las tecnologías de observación satelital para el monitoreo del uso del suelo y cultivos se ha visto ampliamente beneficiada en las últimas décadas por la incorporación de diversas formas de observación terrestre (Granados y Gómez, 2016). 
Se consultaron bases de datos de la superficie sembrada a nivel nacional, estatal y municipal del cultivo, fuentes que permite actualizar continuamente la situación que prevalece y analizar la recuperación de esta plantación y/o verificar su reconversión.

El trabajo de campo consistió en seis muestreos en el periodo julio de 2011 a marzo de 2014, donde se tomaron mediciones en las parcelas cultivadas, para todos los casos se registró su ubicación mediante GPS; en las huertas de limón también se recabaron variables como: la especie, edad del huerto, vigor, fenología, presencia de plagas (manejo), productividad, tipo de riego, incidencia y severidad del HLB.

Por la importancia que poseen las plantaciones de limón y la dinámica de cultivos que presentan por la presencia del HLB, el objetivo de este trabajo fue cuantificar los cambios de cultivos en Armería y Tecomán, además de valorar el potencial de las nuevas plantaciones.

\section{Área en estudio}

El área en estudio (Figura 1) comprende los municipios de Armería y Tecomán del estado de Colima con coordenadas al norte $19^{\circ} 31^{\prime}$, al sur $18^{\circ} 41^{\prime}$ de latitud norte; al este $103^{\circ} 29^{\prime}$ y al oeste $104^{\circ} 41^{\prime}$ de longitud oeste (INEGI, 2014). Es la principal región productora, misma que concentra el $78 \%$ de los predios que cultivan limón mexicano en el estado (SIAP, 2018). 
Guadalupe Rebeca Granados-Ramírez, Raciel Hernández-Hernández. Reconversión de cultivos como resultado de la presencia de huanglongbing en Colima, México

Figura 1. Área en estudio. Municipios de Armería y Tecomán, Colima, México

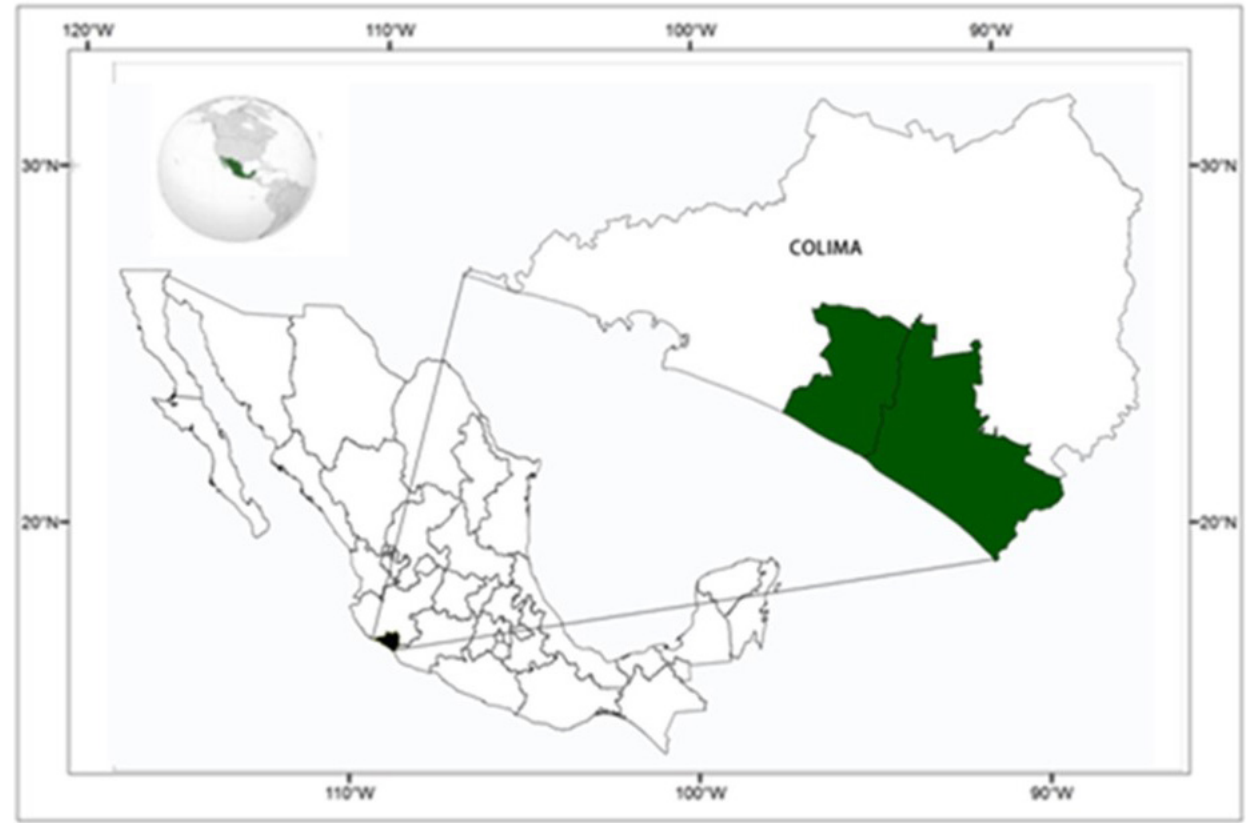

Fuente: INEGI (2014)

\section{Selección de imágenes}

Se eligieron nueve imágenes del satélite Landsat 7 y 8 de enero de 2010 a abril de 2014. El pre-procesamiento de las imágenes implicó la conversión de medidas de niveles digitales a porcentaje de reflectancia, este proceso también permitió hacer la corrección atmosférica mediante el método de calibración radiométrica del cuerpo negro.

La zona en estudio se delimitó a través de recortes con mapas vectoriales municipales disponibles en INEGI; también se construyeron máscaras para las áreas que no presentaban actividad agrícola, tales como lomeríos y zonas de manglares, paran eliminar la interferencia.

\section{Procesamiento}

Para identificar las áreas con vegetación cultivada y aquellas con vegetación silvestre se realizó la composición de colores, combinando las bandas 3,2,1 y 4,3,2 según método (Jensen, 2000). La ubicación de las plantaciones y los datos de campo sirvieron como polígonos de 
entrenamiento, para validar los resultados de las clasificaciones a través de matrices de confusión y el análisis de coeficientes de precisión general. La clasificación supervisada se realizó con el método de máxima similitud, mismo que arrojó los mejores resultados, las clasificaciones se procesaron de forma analítica.

Con los resultados de la clasificación supervisada y a través del uso de las herramientas del Sistema de Información Geográfico QGis se realizó la sobreposición de los mapas que ubican las huertas establecidas para marzo de 2010 (fecha para la cual se da el reporte del primer caso de HLB) y las correspondientes a abril de 2014. El algebra de mapas permitió delimitar áreas sustituidas durante el período 2010-2014.

Finalmente se utilizó información de producción, rendimientos y valor de la producción (estadística contenidas en la Web: SIAP-SAGARPA) para la estimación de los impactos derivados por la sustitución de limón mexicano en la región de Armería y Tecomán en 2017.

\section{Resultados}

\section{Uso del suelo agrícola}

La superficie sembradas en el estado y en los municipios de Armería y Tecomán en el período 2006-2017 se representa en la Figura 2; en este periodo se presentaron paulatinas descensos de la superficie sembrada hasta alcanzar una reducción máxima de 13, 165 ha en el ciclo agrícola 2012, posteriormente se fue incrementando.

La variación de las superficies sembradas se explica también por el cambio de uso de suelo; principalmente el crecimiento de las zonas urbanas, además se identificó el incremento de otras actividades productivas, se incluye la piscicultura y la agricultura protegida. La tendencia de reducción de la superficie establecida de limón se acentuó años posteriores de la aparición del HLB, rápidamente se pasa del orden de las 18,654 ha a las 16, 119 ha. (Figura 2). 
Guadalupe Rebeca Granados-Ramírez, Raciel Hernández-Hernández. Reconversión de cultivos como resultado de la presencia de huanglongbing en Colima, México

Figura 2. Superficie sembrada en los municipios de Armería y Tecomán, Colima

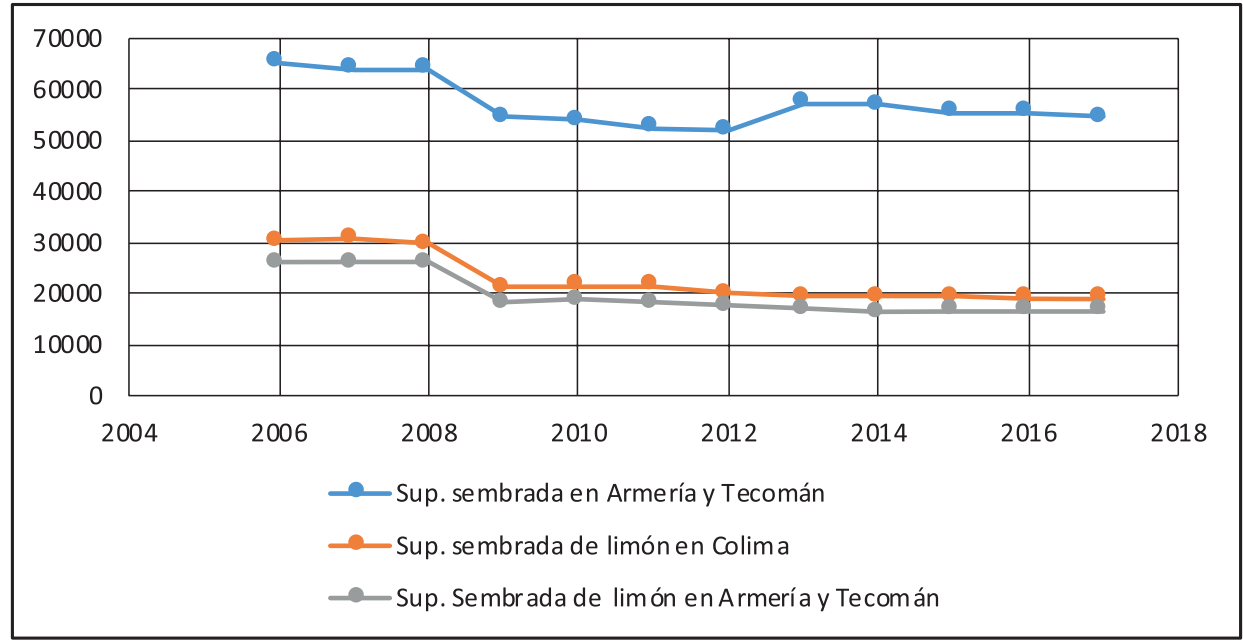

Fuente: Estadística contenidas en la Web: SIAP-SAGARPA

\section{Cultivos en el ciclo agrícola 2010}

Las zonas agrícolas de los municipios de Armería y Tecomán, concentran más del $80 \%$ de la producción de limón del estado de Colima (SIAP, 2018). Otras plantaciones importantes fueron: copra, plátano tabasco, mango (haden, ataulfo, manila y kent), caña de azúcar, papaya maradol y sandia. También se encuentran algunos cultivos anuales como maíz forrajero, sorgo forrajero y hortalizas en superficies reducidas (Figura 3).

En las escenas procesadas de 2010 se observó una alta fragmentación de la tierra, existen parcelas agrícolas menores a una hectárea hasta aquellas con algunas decenas de hectáreas; está heterogeneidad espacial está vinculada a diversas prácticas agronómicas, dependiendo de las plantaciones y cultivos establecidos. 
Figura 3. Plantaciones establecidas en la zona en estudio en 2010

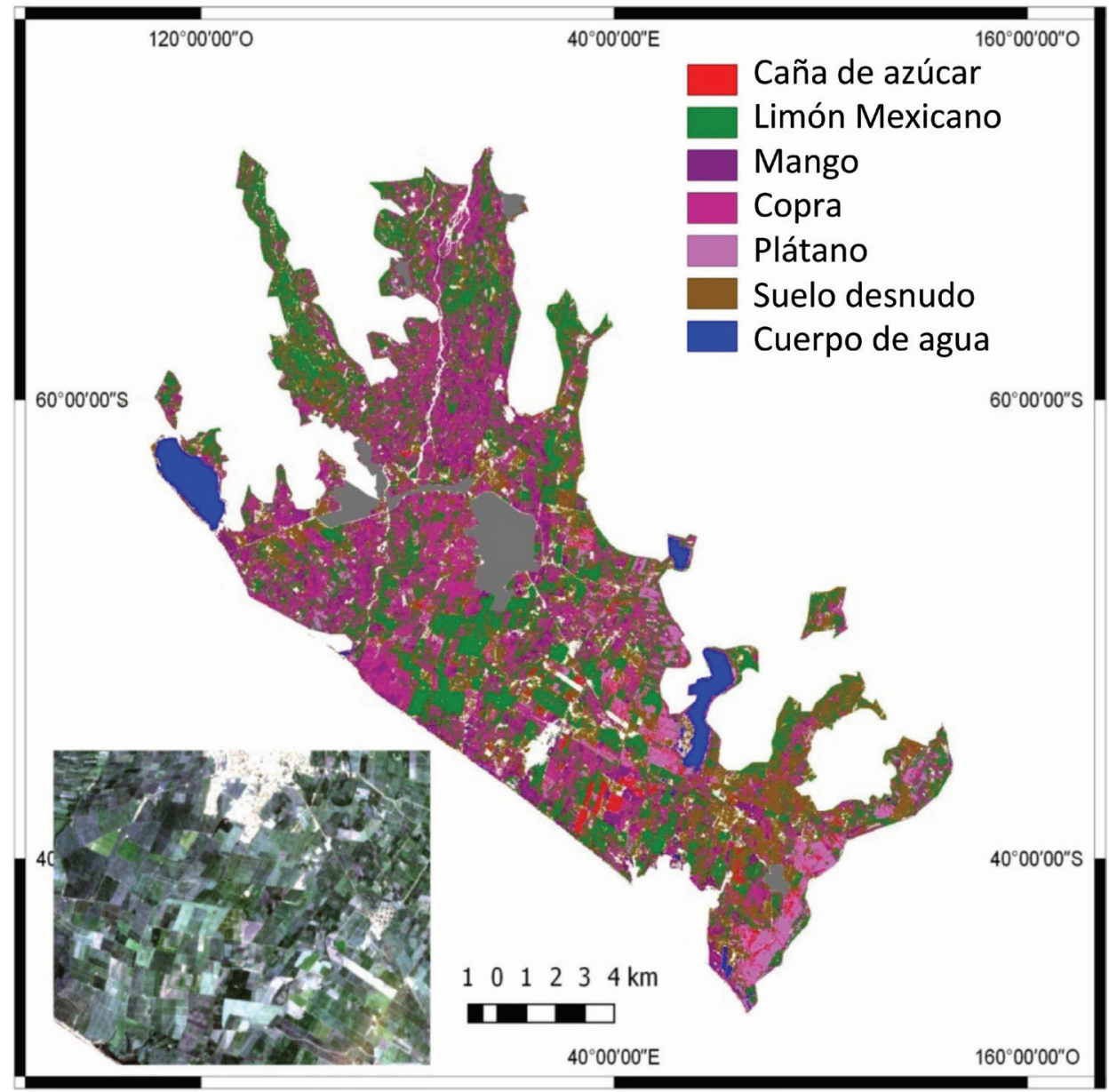

Fuente: Análisis de imágenes Landsat 7 y 8.

En este ciclo el limón agrio mexicano y la copra fueron las plantaciones más extendidas, el limón contó con una superficie de 18,289 ha y una producción de 320,685 ton. Las plantaciones se ubicaron a lo largo y ancho de la superficie agrícola, existieron conglomerados amplios y continuos distribuidos en ambos municipios; el cocotero o copra ocupó 16,139 ha. con una producción de 20,536.5 ton., encontrándose establecidos principalmente en las áreas cercanas a la costa; también fueron ubicadas en los alrededores de Tecomán donde es común encontrarlo asociado con limón 
Guadalupe Rebeca Granados-Ramírez, Raciel Hernández-Hernández. Reconversión de cultivos como resultado de la presencia de huanglongbing en Colima, México

mexicano. La zona platanera se presentó en forma compacta al sur de Tecomán, en las cercanías de las riberas del Río Coahuyana y de la laguna de Amela, estas plantaciones son más dispersa y pequeña en los alrededores de la ciudad de Tecomán; en 2010 se reportó 3,059 ha sembradas con una producción de 83,100 ton. de plátano. Siguiente en superficie ocupada fue el mango con 1,088 ha y 18,492 toneladas. La caña de azúcar se ubicaron en la planicie costera, formando amplios mosaicos en 2010 existió una superficie sembrada de 1,032 con una producción de 88,208 ton (Figura 3).

En el análisis realizado en 2014 (cuatro años de haberse reportado la presencia del HLB) resaltó la presencia de nuevas plantaciones de limón, las cuales se clasificaron en mayores a cinco años y menores a cinco años y limón Persa; también se verifico el incremento de algunos perennes y aparición de otros como la piña, la cual se concentró en pocos productores ubicados hacia el sur-oeste de la ciudad de Tecomán con rumbo hacia la costa, paso de 2010 a 2014 de 48 a 323 ha.; la caña de azúcar, plátano y papaya son los frutales que incrementaron su superficie en este ciclo agrícola (Figura 4). 
Figura 4. Plantaciones establecidas en la zona en estudio 2014

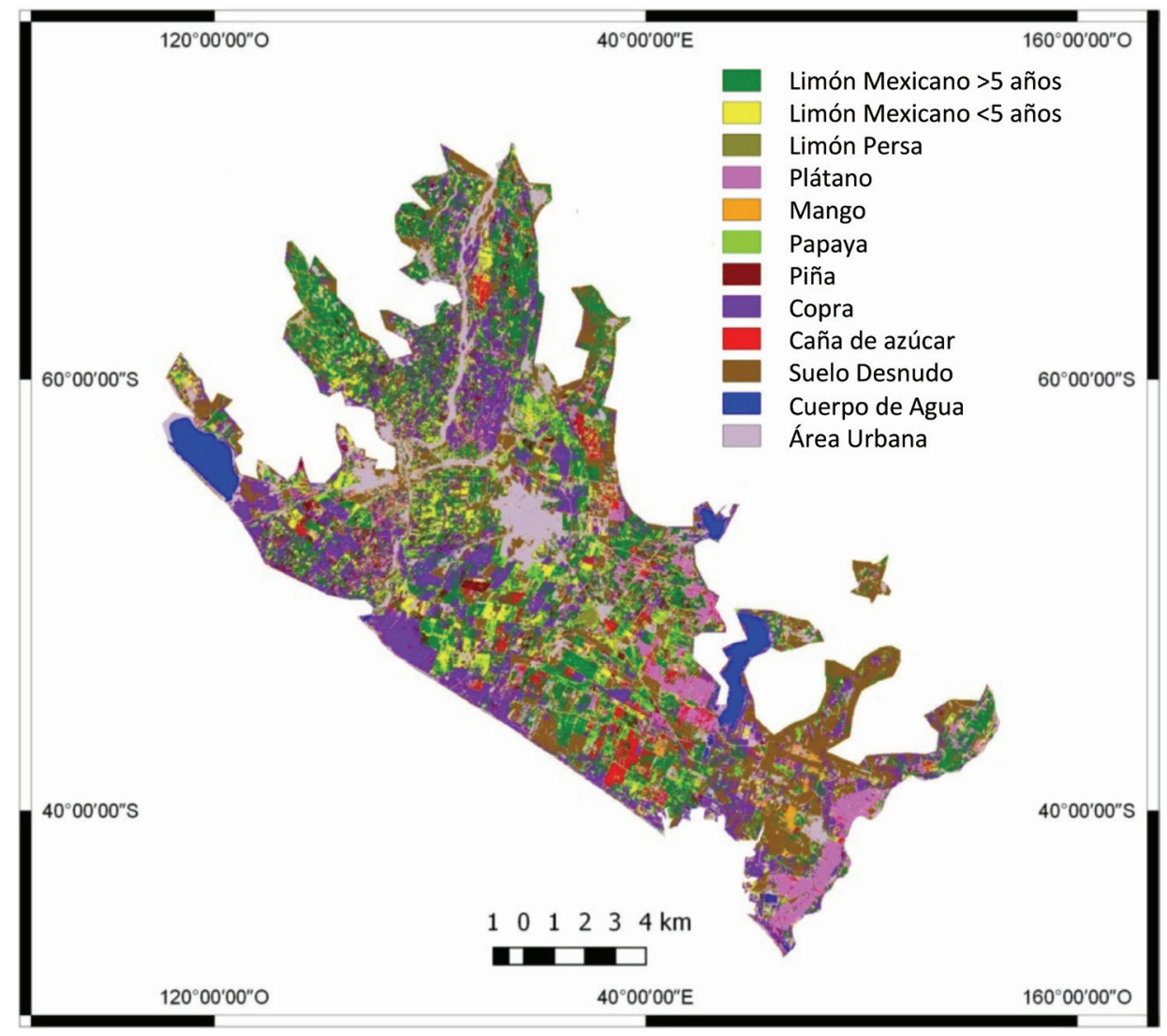

Fuente: Análisis de imágenes Landsat 7 y 8.

Por otro lado, en pequeños valles y lomeríos de la Sierra Madre del Sur y la ribera del Río Armería, se verificó la existencia de huertas de limón mexicano y reducidas superficies de papaya, mango y cultivos anuales.

La tendencia de reducción de la superficie establecida de limón se acentuó años posteriores de la aparición del HLB, rápidamente se pasa del orden de las 18,654 ha a las 16,119 ha., esto se explica por la rápida explosión de la epidemia y a que los protocolos de erradicación fueron adoptados de manera limitada, el monitoreo y análisis de imágenes permitió delimitar áreas donde las huertas fueron eliminadas completamente, principalmente huertas jóvenes con producciones mínimas o aún nulas. 
Guadalupe Rebeca Granados-Ramírez, Raciel Hernández-Hernández. Reconversión de cultivos como resultado de la presencia de huanglongbing en Colima, México

La dinámica de los cultivos en el área de estudio ha presentado importantes cambios a partir de la aparición del HLB y su establecimiento, se observa la sustitución de la superficie sembrada de limón mexicano en el orden de las 2,535 ha de 2010 a 2014, se propició el reemplazo de huertas de cítricos enfermos por nuevas plantaciones, en el orden de las 4,000 ha. El limón persa de reciente introducción registró aproximadamente 560 ha, en 2017, superficie que se está incrementando.

La tendencia de disminución ha tendido a estabilizarse en el orden de los 16,000 ha, hecho que puede ser atribuible a los programas de las organizaciones involucradas en la campaña del HLB, que han tomado las experiencias de otras regiones productoras, como Brasil y E.U.A.; de convivir con la enfermedad. Las estrategias se basan principalmente en el control regional del psilido y la nutrición intensiva de los árboles enfermos, esto último para alargar la vida productiva de los perennes en la región.

A pesar de lo anterior, existen huertas con altos índices de incidencia de la enfermedad, cercanos al 100\%, los cuales a mediano plazo será inevitable la sustitución; el agricultor estará ante la disyuntiva de explorar con cultivos tradicionales de la zona, como plátano, caña de azúcar, mango y cocotero; también cultivos anuales como maíz, sorgo y hortalizas; o bien con cultivos emergentes como la papaya y piña. Una segunda opción es continuar con nuevas plantaciones de limón, con las implicaciones derivadas de la presencia del HLB en la región y nuevas variedades de limón (persa orgánico, limón italiano, limón agrio mexicano orgánico).

Los cambios en los usos del suelo y/o conversión de cultivos en ocasiones se producían sin tener en cuenta las características del territorio, en la actualidad existe cartografía que delimita las zonas agroecológicas adecuadas para la producción agropecuaria y forestal. El potencial productivo de especies vegetales estuvo a cargo del Instituto Nacional de Investigaciones Forestales Agrícolas y Pecuarias INIFAP-México, misma que proporciona información en medios digitales e impresos; información que actualmente apoya a la toma de decisiones de productores, inversionistas y quienes definen las políticas públicas y los programas y proyectos sectoriales para asegurar la producción de alimentos y la conservación de los recursos naturales (Díaz et al., 2012; SAGARPA, 2016).

En la región citrícola de Colima las plantaciones y cultivos seleccionadas para sustituir el limón presentan potencial productivo en gran 
proporción alto. En cuanto a la rentabilidad actual de los cultivos emergentes de acuerdo con la relación beneficio-costo, la papaya es un cultivo rentable. Muestra de lo anterior, se tiene que en 2017 los rendimientos y precio de la papaya superaron al limón. En papaya se registraron rendimientos de 50 ton/ha y limón sólo 9.0; respecto al precio medio rural $\$ 5,976$ por tonelada y 4,605 respectivamente. Además la papaya por su dinamismo comercial es considerada una de las más importantes desde el punto de vista económico (Granados et al., 2015). En cuanto a la piña, esta ha presentado un rendimiento de 70 ton/ha y el precio medio rural en 2017 fue de 5,702 por Ton.

La decisión de una nueva plantación de cítricos implica la disponibilidad de hospedantes de mayor susceptibilidad, al ser plantas jóvenes (SENASICA-DGSV, 2012), por lo que requerirán de un manejo fitosanitario acorde a las normas establecidas por el SENASICA, para evitar que se conviertan en nuevos focos de inóculo de la bacteria.

\section{Huertas de limón sustituidas}

Los impactos observados en Colima donde los niveles de incidencia son altos, llegando incluso al 100\% en algunas huertas; este escenario plantaron la necesidad de sustitución del huerto total en un corto plazo por el alto grado de incidencia de la enfermedad.

En la (Figura 5) se muestra en tonalidades verdes la superficie sustituida entre los años 2010 y 2014. La distribución de las huertas eliminadas es aleatoria, sin seguir un patrón estable, por lo que existan huertas sustituidas por toda la región agrícola.

La pérdida en la productividad en las superficies de limón ha sido considerable, según constan en los datos de rendimiento y valor de la producción reportados para 2017 (SIAP, 2018). Los resultados indican que en promedio se han dejado de producir 189,259.70 ton de fruta, lo que significa una disminución en promedio de $\$ 454,198,260$ pesos mexicanos.

La rentabilidad actual de las plantaciones de limón en Colima, de acuerdo con la relación beneficio-costo, es baja lo que ha obligado a considerar la reconversión productiva como estrategia para generar mejores opciones de producción agrícola (comunicación en campo). 
Guadalupe Rebeca Granados-Ramírez, Raciel Hernández-Hernández. Reconversión de cultivos como resultado de la presencia de huanglongbing en Colima, México

Figura 5. Huertas sustituidas de limón mexicano en el período de 2010 a 2014

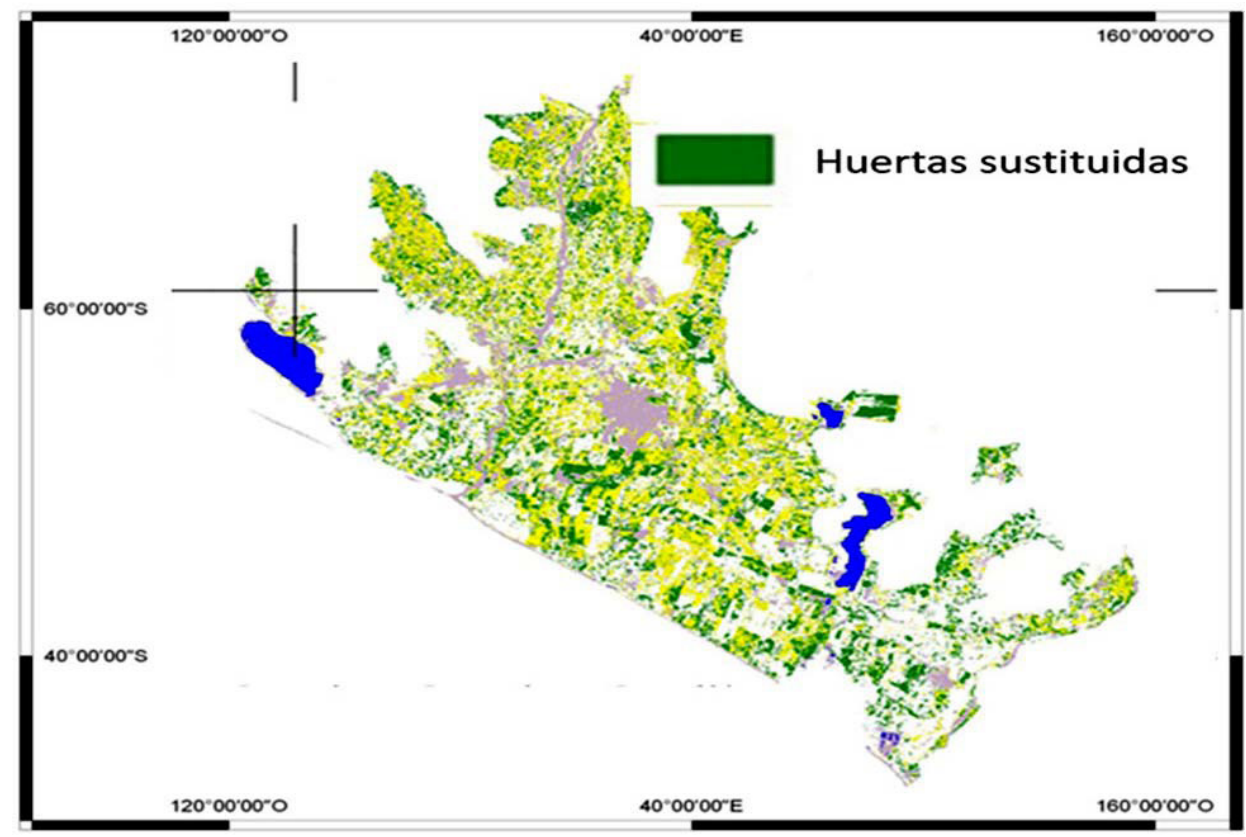

Fuente: Análisis de imágenes Landsat 7 y 8.

El estado de Colima junto con sus principales municipios productores de limón (Armería y Tecomán) ocuparon el primer lugar en la producción de este perenne. Debido a los bajos rendimientos, reducción de superficie sembrada por la presencia del HLB, cambios en el uso del suelo, extensión urbana, el estado de Colima ha perdido su posición como principal productor; en el ciclo agrícola 2017 se reportó a los estados de Michoacán y Veracruz como los principales productores. Cabe resaltar que estos estados junto con otros que reportan menores superficies poseen el potencial productivo alto ya que poseen las condiciones termo pluviométricas óptimas para la producción.

\section{Conclusiones}

Mediante análisis espacial con herramienta SIG; se observó y cuantificó un progresivo cambio de cultivos, nuevas plantaciones y permanencia de plantaciones inocuas; así que las herramientas geotecnológicas representan una alternativa óptima para su monitoreo y análisis de esta plantaciones y de la agricultura en general. 
La presencia del HLB en la región citrícola de Armería y Tecomán a partir de 2010 ha implicado una fuerte inversión para el mantenimiento de las huertas productivas de limón mexicano, debido a la distribución y severa destrucción que ha ocasionado la bacteria causante del HLB en la región.

La sustitución de huertas de limón ha sido lenta, debido a que varios productores han tomado la decisión de convivir con la enfermedad, ya que al ser el limón mexicano un cultivo altamente redituable intentan mantener la productividad de las huertas el mayor tiempo posible. Otros agricultores han adoptado la decisión de renovar las plantaciones de limón, por lo que hace necesario el fortalecimiento de los sistemas de monitoreo permanente del HLB y su vector con herramientas de PR, para contar con información que permita tomar las medidas de manejo que ayuden a mitigar al mínimo las condiciones favorables de dispersión de la enfermedad.

Las condiciones físico-geográficos de Armería y Tecomán son idóneas (fortalezas) para el buen desarrollo de las plantaciones de papaya y piña. Por lo anterior, fue acertada la elección de dichos frutos y se pueden crear nuevos huertos, ya que se garantiza con certeza, será una opción viable para la adquisición de mayores ingresos económicos para los productores. La Carica papaya y Ananas comosus son fitorecursos importantes por el potencial que ofrece en diferentes ámbitos: ya sea en verde, madura, látex (papaína), entre otros . Por tanto, es vital se fomente y fortalezca la investigación en la industria alimenticia para iniciar y perfeccionar la creación de mermeladas, papillas, jugos, deshidratados, polvo cristalizado, puré, almíbar, productos nutracéuticos y farmacéuticos en la región. Igualmente será imperioso generar planes de mercadotecnia para ampliar los mercados de estos nuevos cultivos. 
Guadalupe Rebeca Granados-Ramírez, Raciel Hernández-Hernández. Reconversión de cultivos como resultado de la presencia de huanglongbing en Colima, México

\section{Referencias}

Bové, J. M. (2006). Huanglongbing: A destructive, newly-emerging, century-old disease of citrus. Journal of plant pathology, 7-37.

Colleta, H. D., Targon, M.L. y Takita, M. A. (2004). Detecção do agente causal do greening do citros (Candidatus Liberibacter asiaticus) no estado de São Paulo. Summa Phytopathol. 30, 510.

Díaz, P. G., Guajardo, P. R. A., Medina, G. G., Sánchez, C. I., Soria, R. J., Vázquez, A. M. P., Quijan, C.J. A., Legorreta, P.F. y Ariel, R.C.J. (2012). Potencial productivo de especies agrícolas de importancia socioeconómica en México. $1^{\text {a }}$ Ed INIFAP. Xalapa,Ver., México.

Esquivel-Chávez, F., Valdovinos-Ponce, G., Mora-Aguilera, G., GómezJaimes, R., Velázquez-Monreal, J. J., Manzanilla-Ramírez, M. Á., \& López-Arroyo, J. I. (2012). Análisis histológico foliar de cítricos agrios y naranja dulce con síntomas ocasionados por Candidatus Liberibacter asiaticus. Agrociencia, 46(8), 769-782.

FAOSTAT (2018). Producción de cultivos por país Datos al cierre 2016.

Recuperado de: http://www.fao.org/faostat/en/\#data/QC

Galvão de Miranda, S.H., Oliveira Adami, A. C. y Bassanezi Beozzo R. (2012): Economic impacts of huanglongbing disease in Sao Paulo State. International Association of Agricultural Economists (IAAE). Triennial Conference, Foz do Iguacu, Brazil, August. pp. 1-20. Recuperado de: http://swfrec.ifas.ufl.edu/hlb/database/ pdf/00002960.pdf

García-Ruíz, J.M. y Lana-Renault, N. (2011). Hydrological and erosive consequences of farmland abandonment in Europe, with special reference to the Mediterranean region. Agriculture. Ecosystems and Environment, 140, 317-338.

Granados, R. y G. Gómez R. (2016). Sistemas de información geográfica $\mathrm{y}$ percepción remota en las actividades agrícola. En Reyna Trujillo,T.D.J., M. Vega León y M. Gordillo Orduño (Coord.), Producción, Postproducción y Agrotecnias de Semillas de Hortalizas y Frutas. Coadyuvantes en la Seguridad Alimentaria en México y Cuba, edit. Instituto de Geografía, Ciudad de México, México, 91-102. Recuperado de: www.igeograf.unam.mx/sigg/ utilidades/docs/pdfs/publicaciones/geo_siglo21/otros/semillas hortalizas_final.pdf 
Granados, R., Salceda, R. y Longar M. D. P. (2015). Situación actual y perspectivas tecnológicas para la papaya (Carica papaya L.) en el distrito de Veracruz, Veracruz". Revista mexicana de ciencias agrícolas, 6,4, 749-761.

INEGI Instituto Nacional de Estadística y Geografía (2014). Catálogo Único de Claves de Áreas Geoestadísticas Estatales, Municipales y Localidades. Recuperado de: www.inegi.org.mx/geo/contenidos/ geoestadistica/catalogoclaves.aspx.

Jensen, J. (2000). Remote sensing of the environment: An earth resource perspective. Pearson Education. India.

Juan, J. R. y Díaz, A. R. (2016). Evolución del abandono de tierras de cultivo en la comarca oriental de la Región de Murcia. Boletín de la Asociación de Geógrafos Españoles, 71, 9-29.

Manzanilla-Ramírez, M. A., Robles-González, M. M., Velázquez-Monreal, J.J., Orozco-Santos, M. y Medina-Urrutia, V.M. (2010). Programa en el manejo del huanglongbinng en limón mexicano para el estado de Colima. Segundo taller internacional de plagas cuarentenarias de los citricos. Colima. Recuperado de: http://www.sagarpa.gob.mx/ Delegaciones/sanluispotosi/boletines/Paginas/BOL170811.aspx

Márquez, R. O., Muro, L. R., Escobedo, F. J. R. y Ramírez, J. S. P. (2002). Cultivos alternativos para el altiplano semiárido de México. Agricultura Técnica en México, 2002, 2-28.

Nieto, I. G., Isabel, P. M. y Rey, F. J. S. (2015). Análisis del régimen de incendios forestales y su relación con los cambios de uso del suelo en la Comunidad Autónoma de Madrid (1989-2010). Geofocus: Revista Internacional de Ciencia y Tecnología de la Información Geográfica, 16, 12. Ramírez-García, C., Vera-Castillo, G., Carrillo-Anzures, F. y MagañaTorres, O. S. (2008). El cedro rojo (Cedrela odorata L.) como alternativa de reconversión de terrenos agrícolas en el sur de Tamaulipas. Agricultura técnica en México, 34, 2, 243-250.

Robles-González, M., Velázquez-Monreal, J.J., Manzanilla-Ramírez, M. A., Orozco-Santos, M., Médina-Urrutia, V. M., López-Arroyo, J. I. y Flores-Virgen, R. (2013). Sintomas del Huanglonbing (HLB) en árboles de limón mexicano [Citrus aurantifolia(Christm) Swingle] y su dispersión en el estado de Colima, México. Revista Chapingo. Serie horticultura, 19,1, 15-31. 
Guadalupe Rebeca Granados-Ramírez, Raciel Hernández-Hernández. Reconversión de cultivos como resultado de la presencia de huanglongbing en Colima, México

Salcedo-Baca, D., Hinojosa, R.A., Mora-Aguilera, G., CovarrubiasGutiérrez, I., De Paolis, F.J.R., Mora-Flores, J.S. y CintoraGonzález, C. L. (2010). Evaluación del impacto económico del Huanglongbing (HLB) en la cadena citrícola mexicana. Instituto Interamericano de Cooperación para la Agricultura (IICA), México. pp. 5-78. Recuperado de:www.iica.int/Esp/regiones/norte/mexico/ Publicaciones\%20de\%201a\%20Oficina/B2009e.pdf

SAGARPA Secretaria de Agricultura, Ganadería, Desarrollo Rural, Pesca y Alimentación. (2009). Norma Oficial Mexicana de Emergencia NOM-EM-047-FITO-2009. SAGARPA, México. Recuperado de: http://pflanzengesundheit.jki.bund.de/dokumente/upload/74020 mx3-nom-047-2009citrus-candidatus-liberibacter-kons.pdf

SAGARPA Secretaría de Agricultura, Ganadería, Desarrollo Rural, Pesca y Alimentación. (2018). Atlas Agroalimentario. Servicio de Información Agroalimentaria y Pesquera. Primera Edición, México, 216 p.

SAGARPA- SENASICA. Dirección General de Sanidad Vegetal (2012). Ficha Técnica de HLB Huanglongbing. Recuperado de: https:// www.gob.mx/cms/uploads/attachment/file/147557/Ficha_T_cnica_ Candidatus_Liberibacter_spp.pdf

SIAP Servicio de Información Agroalimentaria y Pesca (2018): Anuario Estadístico de la Producción Agrícola. Recuperado de: http:// infosiap.siap.gob.mx/aagricola_siap_gb/icultivo/index.jsp

Spreen, T. H., \& Baldwin, J. P. (2013). The impact of huanglongbing (HLB) on citrus tree planting in Florida. In Annual Meeting of the Southern Agricultural Economics Association, February (pp. 2-5).

Zatarain, F., Lazaro, P., de Leon, B., Robles, B., Fuentes, C., Montesillo, J. L., y Reyes, R. (2005). Posibilidad de reconversión productiva del distrito de riego 025 Bajo Rio Bravo, Tamaulipas. Anuario, IMTA. México. 
